\title{
Parks for sharks: human exclusion areas outperform no-take marine reserves
}

\author{
Ashley J Frisch ${ }^{1,2 *}$ and Justin R Rizzari ${ }^{3,4}$
}

We collected reef shark population data from a large network of no-take and no-entry reserves (ie human exclusion areas), as well as from fished reefs, in one of the world's most intensively managed marine parks - the Great Barrier Reef of Australia. The sampled reserves have been protected for varying lengths of time, making it possible to use space-for-time chronosequences to infer recovery trajectories of reef shark populations after extractive use is banned, and to compare the effectiveness of shark population recovery in no-take and no-entry reserves. After 20-40 years of protection, density and biomass of sharks in no-entry reserves approached asymptotes (ie plateaus) that were more than double and triple, respectively, those in no-take reserves. These results not only indicate that restoration of near-natural shark populations requires multidecadal time frames, but also clearly demonstrate the superior performance of no-entry reserves in terms of rebuilding shark populations. Ongoing poaching in no-take reserves, which are more difficult for law enforcement to police than no-entry reserves, is the probable cause of the disparity. Given the ubiquitous use of no-take reserves as ecological baselines and the potentially pervasive trophic effects of removing large predators, we argue that current perceptions of the structure and function of natural reef ecosystems may be skewed, which has broad implications for science and management of marine ecosystems

Front Ecol Environ 2019; 17(3): 145-150, doi:10.1002/fee.2003

$\mathrm{N}^{\mathrm{os}}$ o-take marine reserves - areas where all extractive use is forbidden - are often promoted as effective tools for rebuilding overexploited fish and shark populations, and for restoring natural ecosystems (McClanahan et al. 2007; McCook et al. 2010). With few exceptions, well-enforced no-take reserves facilitate rapid build-up of target fish populations (Russ et al. 2008), leading to extensive cascading benefits, such as improved fishery yields in outlying areas and greater biodiversity (Graham et al. 2011). As a result, no-take reserves are often used as baselines (unexploited areas with intact ecology) in studies of community structure and fishing effects (eg Heupel et al. 2009; McCook et al. 2010), and thus have contributed to human perceptions of what undisturbed ecosystems should look like and how they should function. However, most, if not all, previous studies of no-take reserves in coral reef ecosystems have been relatively short in duration $(<10$ years) and are therefore inadequate for detecting the full trajectory of ecological change, or have focused on relatively small, fast-growing fish species (McClanahan et al. 2007; Russ and Alcala 2010). Large, slow-growing predators such as sharks are often overlooked, despite widespread recognition that these species are among the most affected by fishing and the last to recover from overexploitation. Furthermore, on remote coral reefs in the central Pacific, which presumably represent realistic baselines, sharks account for an extraordi-

${ }^{1}$ Reef HQ, Great Barrier Reef Marine Park Authority, Townsville, Australia*(ashley.frisch@gbrmpa.gov.au); ${ }^{2}$ ARC Centre of Excellence for Coral Reef Studies, James Cook University, Townsville, Australia; ${ }^{3}$ School of Life and Environmental Sciences, Deakin University, Geelong, Australia; ${ }^{4}$ Fisheries and Aquaculture Centre, Institute for Marine and Antarctic Studies, University of Tasmania, Hobart, Australia narily high percentage of total fish biomass and are thought to have profound top-down effects on prey demography, habitat structure, and ecosystem productivity (Sandin et al. 2008; McCauley et al. 2010; Bradley et al. 2017). Until researchers can ascertain the population status of large predators like sharks, the integrity of ecosystems within no-take reserves will continue to be tenuous and the amount of time required to fully rebuild exploited reef communities will remain unknown. A major implication of this knowledge gap is that modern perceptions of what constitutes a natural reef ecosystem may be misguided.

The three most abundant shark species on Indo-Pacific coral reefs - the grey reef shark (Carcharhinus amblyrhynchos), blacktip reef shark (Carcharhinus melanopterus), and whitetip reef shark (Triaenodon obesus) (Figure 1, a-c; Rizzari et al. 2014c) - are high-level predators whose ecological roles give them priority status in conservation and management efforts (McCauley et al. 2010; Frisch et al. 2016). However, due to extensive targeting and incidental capture by reef fisheries, reef shark populations have been depleted across much of the Indo-Pacific region (Robbins et al. 2006; Nadon et al. 2012). Although there have been few attempts to specifically manage reef sharks, indirect evidence suggests suitably designed and enforced no-take reserves may help to rebuild reef shark populations (Heupel et al. 2009; Speed et al. 2018). Given the depleted status of reef shark populations and their potential importance to ecosystem function, an evaluation of the effectiveness of no-take reserves for rebuilding reef shark populations is needed.

The Great Barrier Reef (GBR), which extends $2300 \mathrm{~km}$ along the northeast coast of Australia and consists of more 

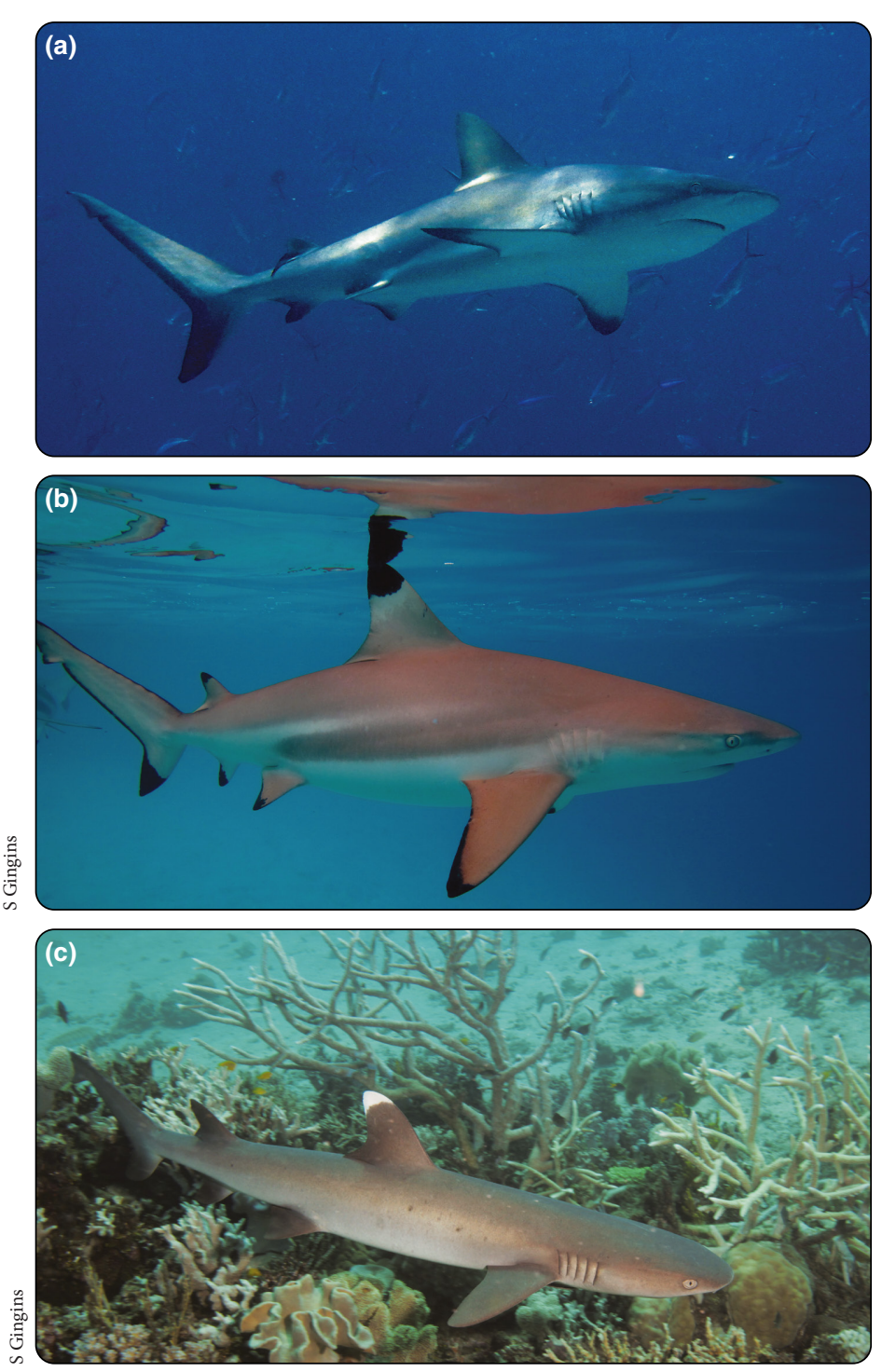

Figure 1. Reef sharks, including (a) grey reef shark (Carcharhinus amblyrhynchos), (b) blacktip reef shark (Carcharhinus melanopterus), and (c) whitetip reef shark (Triaenodon obesus), are slow to recover after cessation of fishing.

than 2500 distinct reefs, is the world's largest coral reef system. Historically, all parts of the GBR were open to fishing and other extractive uses, but a series of no-take reserves were successively introduced between 1980 and 2004, resulting in a large-scale network of no-take reserves that range in age from 14-38 years (as of 2018; WebTable 1). Although no-take reserves are considered the gold standard for marine management, a small number of strictly enforced human exclusion areas (designated here as "no-entry" reserves) were also implemented during the same period, to guard against potential impacts of non-extractive uses (eg boating, SCUBA diving). Due to the exclusion of humans from no-entry reserves, shark population sizes within these areas are largely unknown and have been quantified only once (10 years after being established) and only at a single location (near Lizard Island) (Robbins et al. 2006), which prevents an evaluation of whether shark recovery is ongoing (ie populations are increasing) or complete (ie populations are at or near carrying capacity). The diverse ages of marine reserves within the GBR provide a unique, spatially controlled opportunity to investigate the potential for shark population recovery, and to evaluate the relative effectiveness of no-entry and no-take reserves as tools for shark conservation and management.

Using space-for-time chronosequences, we reconstructed recovery trajectories of reef sharks over four decades of protection from fishing. Given that all extractive activities (eg fishing) are forbidden in both types of reserves, we predicted that reef shark density and biomass would approach asymptotes (ie plateaus) of similar magnitude in both no-entry and no-take reserves, provided that relevant biophysical parameters are also alike (eg coral cover, topographic complexity, reef size, distance from shore).

\section{Methods}

\section{Study sites and data collection}

Using underwater visual surveys (aggregate transect length $=99 \mathrm{~km}$ ), we quantified shark populations at 13 reefs in no-entry reserves, 11 reefs in no-take reserves, and 10 reefs open to fishing, with sample reefs juxtaposed spatially in eight clusters that were distributed across $\sim 1000 \mathrm{~km}$ of the GBR (WebFigures 1 and 2). A SCUBA diver swam slowly ( $14 \mathrm{~m}$ per minute) for 45 minutes along the 6-m depth contour of the fore-reef slope, recording sharks that were observed within $10 \mathrm{~m}$ of the diver (20-m transect width). A flexible tape was used to periodically check transect width, and a GPS unit was towed at the surface to enable calculation of survey area (mean transect length \pm standard error $[\mathrm{SE}]=635 \pm 12 \mathrm{~m}$; mean transect area $\pm \mathrm{SE}=1.21 \pm 0.03$ ha). Two to 16 transects (median = four) were used for each reef, depending on reef size (total transects $=156$ ). Unbalanced sampling was unavoidable because of the large size of transects relative to the size of some reefs and the need for spatial separation between consecutive transects to ensure statistical independence. When a shark was observed, we recorded size (total length, $L_{\mathrm{t}}$ ), species, and any unique characteristics (eg color patterns, scars) to minimize the risk of counting any individual more than once. Previous evaluations of shark behavioral responses toward divers and of shark encounter rates (with and without divers) indicate that this is an effective protocol (Rizzari et al. 2014a). To ensure consistency, we regularly calibrated estimates of $L_{\mathrm{t}}$ using plastic models of different sizes. In five trials with 10 models, differences between estimated and actual $L_{t}$ of models were not significantly different from zero (paired $t_{9} \geq 0.71$, $P \geq 0.50$ ). To gauge the quality of habitat at each reef, we visually estimated live coral cover and topographic complexity in $10-\mathrm{m}^{2}$ quadrats at 5 -minute intervals (nine estimates per transect). Topographic complexity was categorized on a scale of 1 to 5 , where 1 represents a flat, sandy seafloor and 5 
represents a multilayered coral matrix. All surveys were conducted during daylight hours (0800-1700) in good visibility $(\geq 10 \mathrm{~m})$ between 2012 and 2016 .

\section{Data analyses}

Data were pooled across species because $99 \%$ of all sharks observed were either $C$ amblyrhynchos or T obesus (WebTable 1 ), which are similar in terms of life history, trophic function, and catchability (Smith et al. 1998; Frisch et al. 2016). Count data were standardized to units of density (number of sharks per hectare) and length data were converted to biomass using published length-weight conversion formulae (www.fishbase.org). To investigate the relative influence of fishing protection and environmental variables on reef shark density and biomass, we incorporated management zone, coral cover, topographic complexity, reef size, distance from shore, distance to nearest fished reef, and reserve age into linear mixed-effects models (LMM), with reef and latitude set as random effects. LMM analyses were executed in $\mathrm{R}$ using the lmerTest package and residual plots were used to assess model fit. Distance to nearest fished reef was used as a proxy of exposure to legal fishing (ie due to inter-reef movement of sharks) rather than reserve size or distance to reserve boundary, which are unrepresentative parameters due to irregular reserve shape, disproportionate coverage of non-reef habitats, and inconsistent positioning of some noentry reserves within no-take reserves.

To model the recovery trajectories of reef sharks in noentry reserves, we established chronosequences by assigning "ages" to each reef (ie the number of years since protection commenced), with fished reefs assigned an age of zero. Three ecologically meaningful population growth models (asymptotic, logistic, and Gompertz; WebTable 2) were then fitted to shark biomass and population density data using maximum likelihood fits of the non-linear regression ("nls") package in R. For each model, we estimated $r$ (intrinsic rate of increase), $K$ (mean asymptotic density or biomass), the corresponding $95 \%$ confidence intervals (calculated by non-parametric nls bootstrapping) and $R^{2}$, which is the non-linear approximation of the variation explained by each fitted model. Selection of "best" models was based on the smallest Akaike's Information Criterion (AIC) and corrected for small sample size $\left(\mathrm{AIC}_{\mathrm{c}}\right)$, although other candidate models were also considered to have substantial support if difference in $\operatorname{AIC}_{c}\left(\Delta_{i}\right)$ from the "best" model was $<2$. To overcome uncertainty in model selection, and to ensure robust parameter estimations, we therefore also calculated "average" models that were weighted by $\mathrm{AIC}_{\mathfrak{c}}$, as described by Katsanevakis (2006).

\section{Results and discussion}

Weighted average models of shark density and biomass per unit area in no-entry reserves approached asymptotes (0.99
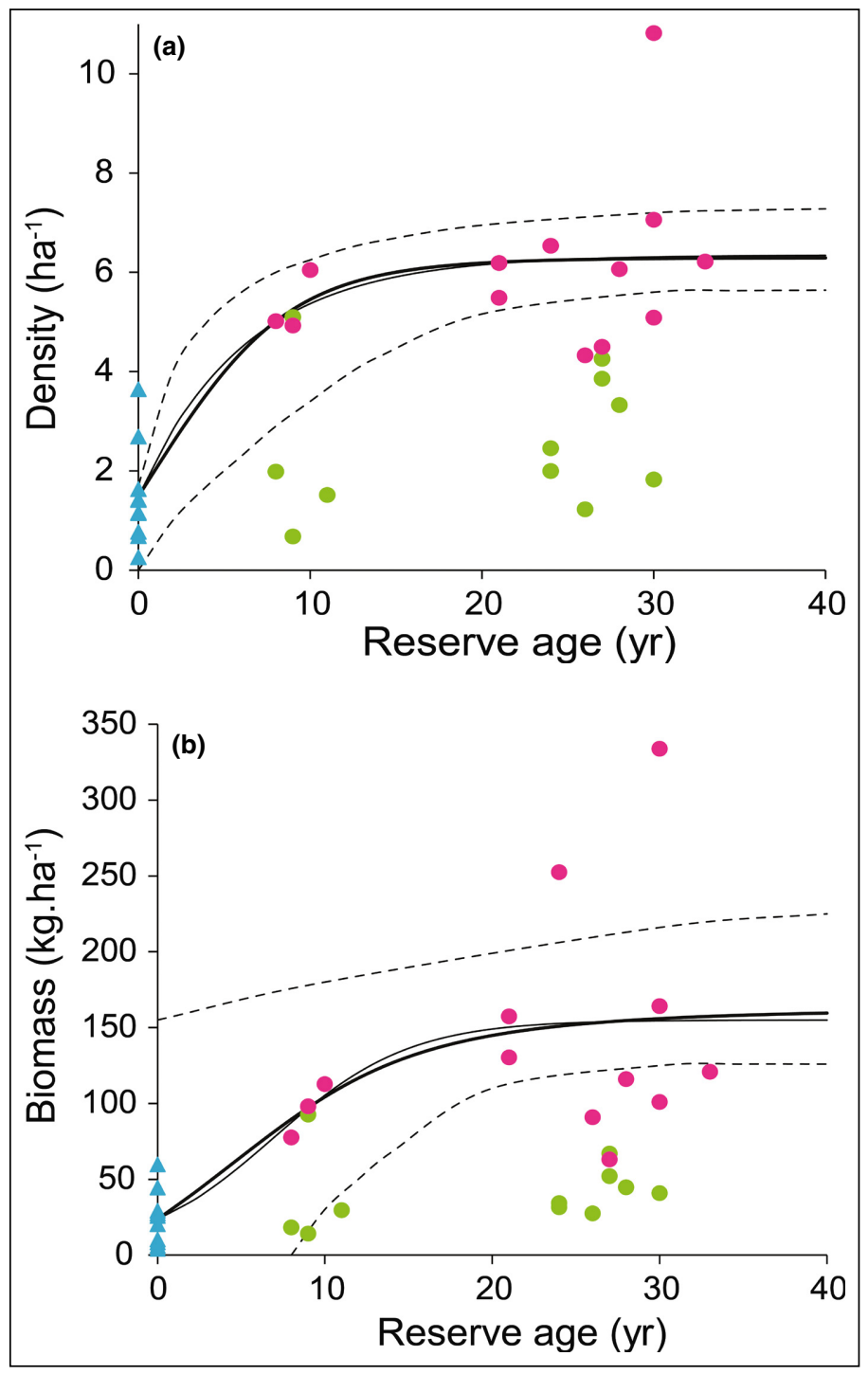

Figure 2. Inferred recovery trajectories based on estimates of (a) density and (b) biomass of reef sharks in no-entry reserves (pink circles) as a function of reserve age. Data points at time zero (blue triangles) are reefs open to fishing. Thick lines are average weighted models, thin lines are best models, and dashed lines are bootstrap 95\% confidence intervals of best models. See Tables 1 and 2 for model parameters. Data from no-take reserves (green circles) are shown for comparison.

K) after 23 years and 45 years, respectively (Figure 2, a and b; Tables 1 and 2), suggesting that two to four decades of stringent protection are required to restore near-natural shark populations in the GBR system. This timeframe is two to three times longer than the recovery period reported for $C$ amblyrhynchos at Ashmore Reef, a protected atoll in the Indian Ocean (Speed et al. 2018). However, our data are consistent with expectations based on intrinsic rates of increase (Smith et al. 1998) and population growth models for reef sharks in the GBR (Hisano et al. 2011). Therefore, the relatively rapid (8-12 years) recovery of shark populations at Ashmore Reef is possibly not representative of shark populations in the GBR or elsewhere. Given that knowledge of recovery rates is important for managing expectations 
Table 1. Estimates of model parameters for reef shark density

\begin{tabular}{|c|c|c|c|c|c|c|c|c|}
\hline Model & $r( \pm \mathrm{Cl})\left[\mathrm{yr}^{-1}\right]$ & $\begin{array}{l}K( \pm \mathrm{Cl}) \\
{\left[\mathrm{ha}^{-1} \text { or kg ha }\right.} \\
-1\end{array}$ & Years to $0.95 \mathrm{~K}$ & Years to $0.99 \mathrm{~K}$ & $R^{2}$ & AIC $_{c}$ & $\Delta_{i}$ & $w_{i}(\%)$ \\
\hline Asymptotic & $0.16(0.04-0.39)$ & $6.4(5.6-8.6)$ & 17 & 27 & 0.75 & 87.96 & 0 & 34.2 \\
\hline Gompertz & $0.23(0.09-0.51)$ & $6.3(5.6-7.9)$ & 14 & 21 & 0.74 & 88.03 & 0.07 & 33.1 \\
\hline Logistic & $0.32(0.16-0.58)$ & $6.3(5.6-7.3)$ & 13 & 18 & 0.74 & 88.05 & 0.10 & 32.7 \\
\hline Weighted average & $0.24(0.00-0.67)$ & $6.3(4.4-8.2)$ & 15 & 23 & - & - & - & - \\
\hline
\end{tabular}

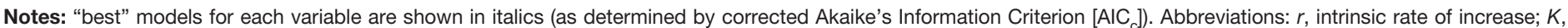
mean asymptotic density or biomass; $\mathrm{Cl}, 95 \%$ confidence intervals; $\Delta_{i}$, Akaike differences; $w_{i}$, Akaike weights.

about the performance of marine reserves, our results highlight the importance of long-term (multidecadal) approaches to conservation and management of shark populations.

As expected, we found that mean density and biomass of sharks were higher in no-take reserves than in areas open to fishing, which supports the notion that no-take reserves are effective at protecting a portion of reef shark populations from fishing (Heupel et al. 2009). However, we found that mean density and biomass of sharks were significantly higher in noentry reserves than in no-take reserves (Figure 3, a and b). In addition, the estimated ratio of fished-to-unfished shark biomass was very similar to ratios elsewhere in the Pacific Ocean (DeMartini et al. 2008; Williams et al. 2011; Friedlander et al. 2014) but only when no-entry reserves (and not no-take reserves) were used to estimate unfished biomass (Figure 3c). Although there is no theoretical basis for expecting population differences of this magnitude between no-entry and no-take reserves, these results clearly demonstrate that no-entry reserves outperform no-take reserves at sustaining shark populations in the GBR.

We contend that illegal fishing is the most likely cause of differential shark populations between no-entry and no-take reserves (see also Robbins et al. 2006). Sharks are seldom directly targeted by the GBR line fishery but they are frequent bycatch, and an unknown but potentially high proportion of sharks die after release due to injuries. Although all extractive activities (eg fishing) are forbidden in both types of reserves, catch-laden fishing vessels are allowed to transit and anchor in no-take reserves, which complicates enforcement (ie evidence of fishing is needed for prosecution). In contrast, no-entry reserves are relatively easy to police via aerial surveillance and satellite monitoring (evidence of fishing is not needed for prosecution), such that fisher compliance tends to be greater within no-entry reserves than for no-take reserves (J Aumend pers comm). Despite extensive enforcement operations by government authorities, recent research indicates that the prevalence of illegal fishing is substantial (3-18\% of recreational fishers admit to fishing illegally within the past year; Bergseth et al. 2017). Furthermore, population viability analyses indicate that even low levels of fishing mortality can substantially reduce reef shark populations (Robbins et al. 2006). The dominant reef shark species at the GBR (C amblyrhynchos and T obesus) are slow growing and late maturing, and have smaller broods than other fishes (Smith et al. 1998). Together, these traits tend to curb population growth rates (9-15 years doubling time) and increase vulnerability to overfishing (Smith et al. 1998). Thus, illegal fishing does not need to be intense to deplete shark populations.

Due to the scarcity of unexploited coral reefs at local and global scales, no-take reserves are often used as baselines (unexploited areas with intact ecology) in studies of community structure and fishing effects and, as such, often influence human perceptions of what undisturbed ecosystems should look like and how they should function. Since no-take reserves at the GBR sustain only $\sim 30 \%$ of unexploited shark biomass (Figure $3 b$ ), top-down trophic effects within no-take reserves likely are dampened, which may have a broad range of cascading effects on other ecosystem components (eg Rizzari et al. $2014 \mathrm{~b}$ ). We therefore question the suitability of no-take reserves as ecological baselines and argue that modern perceptions of what constitutes a natural reef ecosystem may be inaccurate (ie shifting baseline syndrome).

Table 2. Estimates of model parameters for reef shark biomass

\begin{tabular}{|c|c|c|c|c|c|c|c|c|}
\hline Model & $r( \pm \mathrm{CI})\left[\mathrm{yr}^{-1}\right]$ & $\begin{array}{l}K( \pm \mathrm{Cl}) \\
{\left[\mathrm{ha}^{-1} \text { or kg ha }\right.} \\
\end{array}$ & Years to $0.95 K$ & Years to $0.99 \mathrm{~K}$ & $R^{2}$ & $\mathrm{AIC}_{\mathrm{c}}$ & $\Delta_{i}$ & $w_{i}(\%)$ \\
\hline Asymptotic & $0.08(0.01-0.35)$ & $173(131-710)$ & 37 & 59 & 0.57 & 257.81 & 0.12 & 32.2 \\
\hline Gompertz & $0.15(0.03-0.66)$ & 159 (127-493) & 24 & 35 & 0.57 & 257.73 & 0.04 & 33.6 \\
\hline Logistic & $0.25(0.07-1.18)$ & $155(125-313)$ & 19 & 26 & 0.57 & 257.69 & 0 & 34.2 \\
\hline Weighted average & $0.16(0.00-0.59)$ & 162 (59-291) & 28 & 45 & - & - & - & - \\
\hline
\end{tabular}

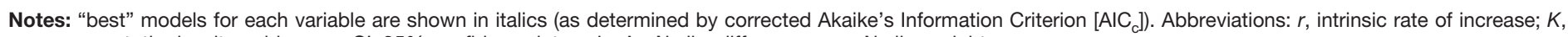
mean asymptotic density or biomass; $\mathrm{Cl}, 95 \%$ confidence intervals; $\Delta_{i}$, Akaike differences; $w_{i}$, Akaike weights. 


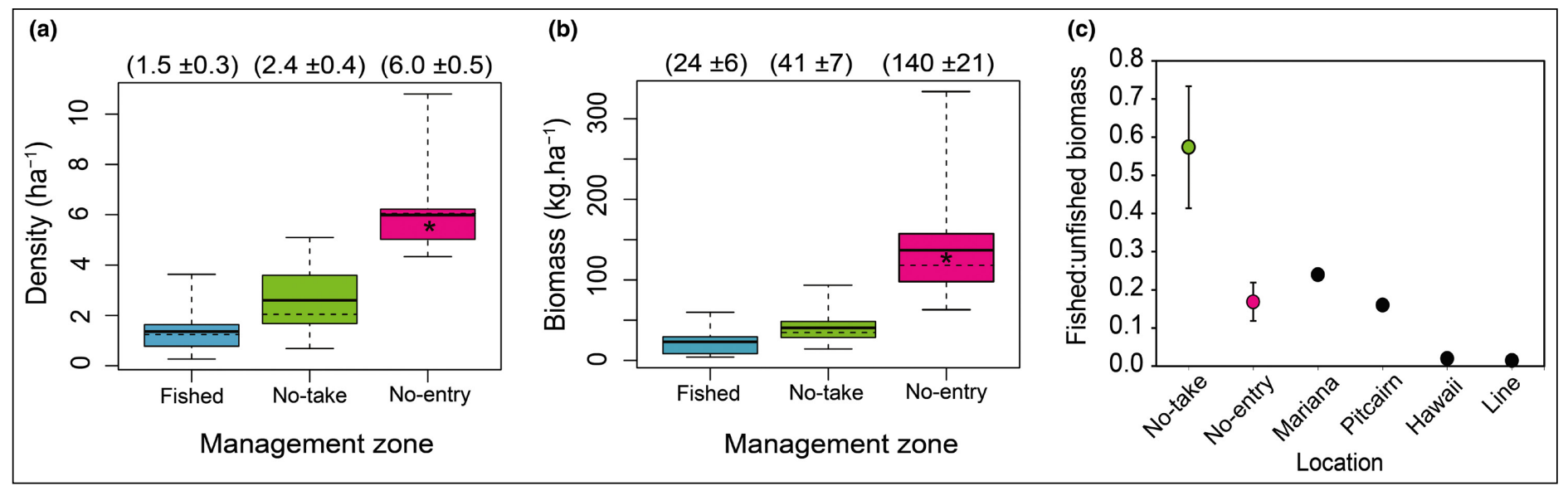

Figure 3. Boxplots of shark (a) density and (b) biomass in fished ( $n=10)$, no-take $(n=11)$, and no-entry $(n=13)$ zones of the Great Barrier Reef (GBR). Boxplots show mean (solid horizontal line), median (dashed horizontal line), interquartile range (box), and range (whiskers). Mean values ( \pm standard error, $\mathrm{SE}$ ) are shown in parentheses above panels (a) and (b). Asterisks $\left(^{*}\right)$ denote groups that are significantly different (also see WebTable 3). (c) Ratio of fishedto-unfished shark biomass in no-take and no-entry reserves at the GBR ( \pm SE) and representative Pacific Islands (data from DeMartini et al. 2008; Williams et al. 2011; Friedlander et al. 2014). A ratio of 1 indicates no difference in shark biomass between fished and unfished reefs.

Large, mobile predators are notoriously difficult to study, and several potential biases warrant consideration. First, although reef sharks can migrate between reefs (Heupel et al. 2010; Espinoza et al. 2015), most individuals are philopatric (tend to remain near or return to the same area) and typically stay on single reefs for long periods of time (Papastamatiou et al. 2010; Whitney et al. 2012; Vianna et al. 2013). Therefore, inter-reef, and thus inter-reserve, movements of reef sharks are probably too infrequent to generate bias in relation to management zone (Rizzari et al. 2014a). Furthermore, distance-tonearest-fished-reef was very similar for both types of reserves (no-entry mean \pm SE: $8.5 \pm 1.9 \mathrm{~km}$; no-take mean \pm SE: $8.1 \pm$ $1.2 \mathrm{~km} ; t_{22}=0.18, P=0.86$ ), suggesting that exposure to legal fishing from cross-border shark movements should be equivalent between reserve types. Second, no-entry reserves, no-take reserves, and fished reefs represent a strong, increasing spectrum of interaction between humans and sharks. If sharks that are unaccustomed to humans (from no-entry reserves) are more likely to approach divers than sharks that are accustomed to humans (from no-take reserves and fished areas), then diver-based population estimates may be biased. However, we obtained consistent results via multiple diver-dependent and diver-independent methods, and multiple lines of empirical evidence demonstrate that any biases in shark behavior toward humans are consistent across management zones (Rizzari et al. 2014a). Finally, although biophysical differences between reefs may affect carrying capacities $(K)$ and population growth rates $(r)$ of sharks, LMM analysis confirms that any inter-reef differences in coral cover, topographic complexity, reef size, and distance from shore (a proxy for water quality and primary productivity) were overwhelmed by differences arising from management status (WebFigure 3; WebTable 3).

No-take marine reserves are currently considered the gold standard for marine management, but there have been few attempts to evaluate (1) whether no-take reserves successfully restore natural systems, particularly regarding populations of large predators, and (2) how long the recovery process may take. Despite the GBR being one of the most intensively managed marine parks in the world and an outstanding example of the rapid, post-protection build-up of target fish populations (Russ et al. 2008), our results indicate that no-take reserves in the GBR fall short of restoring shark populations to nearnatural levels, and that at least 20 to 40 years of strong protection (eg human exclusion) are required to regain near-natural systems with shark populations at or near carrying capacity. Due to the potentially pervasive trophic effects of large predators (eg prey consumption and redistribution; McCauley et al. 2010; Rizzari et al. 2014b), existing no-take reserves within the GBR may have endured subtle ecological changes that not only distort current perceptions of natural ecosystems but also diminish the utility of no-take reserves as ecological baselines. Although implementation of more and larger no-entry reserves may address the problem, this approach reduces opportunities for non-extractive uses, and is therefore likely to be unpopular and politically undesirable. An alternative or complementary approach is to seek better compliance from fishers via enhanced enforcement, education, and/or stewardship. Current expenditures on these and other management activities are minor relative to the economic value of the GBR ( $\sim \mathrm{AU} \$ 37$ million value versus $\sim \mathrm{AU} \$ 5.5$ billion cost for management; McCook et al. 2010), justifying additional investments in compliance-related activities. With better compliance, no-take reserves may yield even better conservation results than previously seen, although full recovery of all trophic levels, including levels occupied by reef sharks, will likely require several decades.

\section{Acknowledgements}

B Moore, J Aumend, and F Molloy provided technical and editorial assistance, and S Gingins provided two photographs 
used in the figures. Funding was provided by the Lizard Island Research Station and the Save Our Seas Foundation. Permission to access no-entry reserves was granted by the GBR Marine Park Authority (permit G13/36059).

\section{References}

Bergseth BJ, Williamson DH, Russ GR, et al. 2017. A social-ecological approach to assessing and managing poaching by recreational fishers. Front Ecol Environ 15: 67-73.

Bradley D, Conklin E, Papastamatiou YP, et al. 2017. Resetting predator baselines in coral reef ecosystems. Sci Rep-UK 7: 43131.

DeMartini EE, Friedlander AM, Sandin SA, et al. 2008. Differences in fish-assemblage structure between fished and unfished atolls in the northern Line Islands, central Pacific. Mar Ecol-Prog Ser 365: 199-215.

Espinoza M, Heupel MR, Tobin AJ, et al. 2015. Residency patterns and movements of grey reef sharks (Carcharhinus amblyrhynchos) in semi-isolated coral reef habitats. Mar Biol 162: 343-58.

Friedlander AM, Caselle JE, Ballesteros E, et al. 2014. The real bounty: marine biodiversity in the Pitcairn Islands. PLoS ONE 9: e100142.

Frisch AJ, Ireland M, Rizzari JR, et al. 2016. Reassessing the trophic role of reef sharks as apex predators on coral reefs. Coral Reefs 35: 459-72.

Graham NAJ, Ainsworth TD, Baird AH, et al. 2011. From microbes to people: tractable benefits of no-take areas for coral reefs. Oceanogr Mar Biol 49: 117-48.

Heupel MR, Simpfendorfer CA, and Fitzpatrick R. 2010. Large-scale movement and reef fidelity of grey reef sharks. PLOS ONE 5: e9650.

Heupel MR, Williams AJ, Welch DJ, et al. 2009. Effects of fishing on tropical reef associated shark populations on the Great Barrier Reef. Fish Res 95: 350-61.

Hisano M, Connolly SR, and Robbins WD. 2011. Population growth rates of reef sharks with and without fishing on the Great Barrier Reef: robust estimation with multiple models. PLoS ONE 6: e25028.

Katsanevakis S. 2006. Modelling fish growth: model selection, multimodel inference and model selection uncertainty. Fish Res 81: 229-35.

McCauley DJ, Micheli F, Young HS, et al. 2010. Acute effects of removing large fish from a near-pristine coral reef. Mar Biol 157: 2739-50.

McClanahan TR, Graham NAJ, Calnan JM, et al. 2007. Toward pristine biomass: reef fish recovery in coral reef marine protected areas in Kenya. Ecol Appl 17: 1055-67.

McCook LJ, Ayling T, Cappo M, et al. 2010. Adaptive management of the Great Barrier Reef: a globally significant demonstration of the benefits of networks of marine reserves. P Natl Acad Sci USA 107: 18278-85.

Nadon MO, Baum JK, Williams ID, et al. 2012. Re-creating missing population baselines for Pacific reef sharks. Conserv Biol 26: 493503.

Papastamatiou YP, Friedlander AM, Caselle JE, et al. 2010. Longterm movement patterns and trophic ecology of blacktip reef sharks (Carcharhinus melanopterus) at Palmyra Atoll. J Exp Mar Biol Ecol 386: 94-102.

Rizzari JR, Frisch AJ, and Connolly SR. 2014a. How robust are estimates of coral reef shark depletion? Biol Conserv 176: 39-47.

Rizzari JR, Frisch AJ, Hoey AS, et al. 2014b. Not worth the risk: apex predators suppress herbivory on coral reefs. Oikos 123: 829-36.

Rizzari JR, Frisch AJ, and Magnenat KA. 2014c. Diversity, abundance, and distribution of reef sharks on outer-shelf reefs of the Great Barrier Reef, Australia. Mar Biol 161: 2847-55.

Robbins WD, Hisano M, Connolly SR, et al. 2006. Ongoing collapse of coral-reef shark populations. Curr Biol 16: 2314-19.

Russ GR and Alcala AC. 2010. Decadal-scale rebuilding of predator biomass in Philippine marine reserves. Oecologia 163: 1103-06.

Russ GR, Cheal AJ, Dolman AM, et al. 2008. Rapid increase in fish numbers follows creation of world's largest marine reserve network. Curr Biol 18: R514-15.

Sandin SA, Smith JE, DeMartini EE, et al. 2008. Baselines and degradation of coral reefs in the Northern Line Islands. PLoS ONE 3: e1548.

Smith SE, Au DW, and Show C. 1998. Intrinsic rebound potentials of 26 species of Pacific sharks. Mar Freshwater Res 49: 663-78.

Speed CW, Cappo M, and Meekan MG. 2018. Evidence for rapid recovery of shark populations within a coral reef marine protected area. Biol Conserv 220: 308-19.

Vianna GMS, Meekan MG, Meeuwig JJ, et al. 2013. Environmental influences on patterns of vertical movement and site fidelity of grey reef sharks (Carcharhinus amblyrhynchos) at aggregation sites. PLoS ONE 8: e60331.

Whitney NM, Pyle RL, Holland KN, et al. 2012. Movements, reproductive seasonality, and fisheries interactions in the whitetip reef shark (Triaenodon obesus) from community-contributed photographs. Environ Biol Fish 93: 121-36.

Williams ID, Richards BL, Sandin SA, et al. 2011. Differences in reef fish assemblages between populated and remote reefs spanning multiple archipelagos across the central and western Pacific. J Mar Biol 2011: 1-14.

\section{Supporting Information}

Additional, web-only material may be found in the online version of this article at http://onlinelibrary.wiley.com/doi/ 10.1002/fee.2003/suppinfo 